DOI 10.37882/2223-2982.2021.02.30

\title{
ЯЗЫКОВОЙ ПОРТФОЛИО КАК СПОСОБ СИСТЕМНОЙ ОРГАНИЗАЦИИ ПРОЦЕССА ОБУЧЕНИЯ ИНОСТРАННОМУ ЯЗЫКУ
}

\section{LANGUAGE PORTFOLIO AS A METHOD OF SYSTEMIC ORGANIZATION OF THE PROCESS OF LEARNING A FOREIGN LANGUAGE}

V. Sobolev

Summary: The article attempts to systematically analyze the new challenges and factors that have emerged recently and significantly affect the educational process, in particular on the process of learning a foreign language. A number of theses are outlined that formulate the urgent need to adjust the methods of teaching a foreign language withing the framework of modern realities. The article describes an approximate technology of teaching a foreign language, as well as independent work of students on the basis of the so-called "Language Portfolio». Based on the concrete definition and specification of educational goals the format of language portfolio is presented and a description of the technology for working with it is given.

Keywords: educational goals, language portfolio, foreign language, motivation, teaching technologies, independent self-development, assessment of knowledge and skills.
B последнее время в мире происходят существенные изменения, вызванные различными причинами экономическими, политическими, эпидемиологическими, психологическими. Все стороны гуманитарной жизни мирового общества испытывают влияние этих изменений на себе. Система образования и, в частности, система обучения иностранным языкам также не осталась в стороне. Безусловно, главным доминирующим фактором, влияющим на образовательный процесс, стала пандемия коронавирусной инфекции. Появившись на свет в конце 2019 года, она в течение 2020 года буквальным образом сокрушила многие принятые стандарты жизни и бытовые стереотипы людей. И сейчас, в начале 2021 года, ситуация продолжает оставаться тревожной, и пока нет более-менее точных прогнозов в отношении будущего развития COVID-19.

Пандемия решительным образом воздействовала на образовательный процесс. Появились различные формы дистанционного обучения, усилилось внимание педагогов к развитию методов самостоятельного образования, возникли разнообразные форматы использова-

\author{
Соболев Вадим Викторович \\ К.п.н., профессор, Военный Университет МО РФ, Москва \\ sob100vad@mail.ru
}

Аннотация: В статье сделана попытка системного анализа возникших в последнее время новых вызовов и факторов, оказывающих существенное влияние на образовательный процесс, в частности, на процесс изучения иностранного языка. Обозначен ряд тезисов, формулирующих насущную потребность в корректировке методики обучения иностранному языку в рамках современных реалий. В статье описана примерная технология преподавания иностранного языка, а также самостоятельной работы учащихся на базе т.н. «языкового портфолио». На основе конкретизации учебных целей представлен формат «языкового портфолио» и дано описание технологии работы с ним.

Ключевые слова: учебные цели, языковой портфолио, иностранный язык, мотивация, технологии обучения, самостоятельное развитие, оценка знаний и умений.

ния интернет-ресурсов, но при этом в образовательной системе частым явлением стали карантины, локдауны и прочие запретительные меры. Практически все вузы и школы сегодня стараются изыскать наиболее оптимальные схемы обучения, но пока многие эксперты скептически относятся даже к продвинутым схемам «дистанта». Специалисты, занимающиеся преподаванием иностранных языков на разных уровнях, отчетливо осознают проблематику и сложность возникших вызовов.

Кроме того, наблюдается действие и других факторов, влияющих на качество учебного процесса. Среди них можно назвать следующие:

- Рост темпа устаревания учебных материалов в результате ускоренной динамики изменения самих жизненных реалий, в том числе, и в тех сферах деятельности, в которых планируется работа выпускников нашего вуза - в сферах вооружений, технологий, инноваций, политических практик, межкультурных связей. Параллельно с этим происходят форсированные подвижки и коррективы в самих языках - как следствие политики глобали- 
зации, тотального продвижения интернета и социальных сетей, с одной стороны, и как следствие языковой политики многих государств, направленной на очищение своих национальных языков от внешних заимствований, с другой стороны. В этом плане очень показательной представляется политика властей Исламской Республики Иран, проводимой главным охранителем национального языка - Академией персидского языка и литературы (Фархангестан). Лексический состав персидского языка изменился разительно за последние годы, и важно отметить, что этот процесс нравится далеко не многим в самом Иране. Обозначенный фактор определенно требует более динамичного учета реалий при разработке и отборе учебных материалов.

- Снижение объема очной учебной нагрузки, вызванное, большей частью, перераспределением учебного времени на другие предметы (применительно к нашему вузу). В расписании появляются новые учебные дисциплины, требующие, по мнению заказчиков и организаторов учебного процесса, отдельного внимания. Сегодня можно утверждать, что объем учебных аудиторных часов по предмету «практический курс первого иностранного языка» снизился за последние несколько лет примерно на 20-30 процентов.

- Неполная ясность перспектив трудоустройства после завершения обучения. Данная тема обозначена в статье применительно к нашему вузу в части тех учащихся, кто обучается по специальности «Перевод и переводоведение». Указанный фактор, несомненно, влияет на уровень мотивации обучения.

- Запретительные меры в вопросе соблюдения безопасности, в частности, в вопросе пользования интернетом и мобильными девайсами. Безусловно, это кардинально ограничивает доступ обучаемых к пользованию разными учебными и языковыми источниками, как, например, к прослушиванию аутентичных аудиотекстов, к чтению разнотематических сообщений иранских СМИ, к просмотру оригинальных фильмов, видеороликов. Конечно, при этом понятно, что риски возможных кибератак на информационные ресурсы нашей армии превалируют по своему значению над этими задачами. Надеемся, что планы по созданию изолированного суверенного интернета для наших военных получат свое разрешение в недалеком будущем.

- Организационные сложности, а именно сравнительно низкий уровень построения самостоятельной подготовки обучаемых. Причина этого заключается в том, что, с одной стороны, сами курсанты зачастую не владеют навыками эффективной са- мостоятельной работы, не всегда правильно расставляют приоритеты, а, с другой стороны, на этот процесс влияют и известные армейские реалии, когда прописанный распорядок самоподготовки нарушается и курсанты занимаются решением неучебных задач.

- Последний фактор - избыточные, на наш взгляд, документооборот и отчетность, возложенные на учебные кафедры и преподавателей.

Подводя итог сказанному, можно утверждать, что действие указанных факторов отрицательно влияет на качество языковой подготовки и требует корректировки систем и методов обучения, практик и процедур образовательного процесса. Анализируя описанные выше вызовы и обстоятельства, можно сформулировать возможные ответы и действия. Назовем несколько базовых направлений настройки учебного процесса.

Во-первых, следует провести более четкую конкретизацию и систематизацию учебных целей, вывести их из координат сложных и заумных формулировок, рамок теоретических дискурсов и представить их описание в доступной для каждого учащегося форме. При этом описание учебных целей должно максимально соответствовать профессиональным требованиям будущей работы выпускников.

Во-вторых, необходима системная работа по обеспечению процесса современными и функциональными учебными материалами. Нужна разработка собственных учебников и пособий, их приобретение или обеспечение доступа в цифровом пространстве к учебникам других отечественных вузов, учебников других стран, прежде всего иранских пособий, англо-персоязычных пособий. При этом важной задачей является разработка т.н. «гида-путеводителя», чтобы преподаватели и обучаемые могли свободно ориентироваться в списке учебной литературы, представлять себе, где расположены и представлены интересующие их на каждом моменте обучения материалы.

B-третьих, обучаемых нужно снабдить технологиями, системой упражнений самостоятельной работы с учебными материалами, образно говоря, важно предоставить учащимся ту самую «удочку», с помощью которой они смогут сами ловить рыбу. Особенно важны в этой связи четкие методические указания в таких вопросах, как, например, методически правильно слушать персоязычные аудиотексты и учиться быстро их понимать, как работать с грамматическим материалом и правильно его использовать в речи, как развивать навыки разговорной речи в стандартных диалогах общения. В данной статье у нас нет возможности подробно осветить эти вопросы, поэтому они станут предметом следующих научных и 
методических исследований.

B-четвертых, учебный процесс должен быть постоянно управляемым. Как сами аудиторные занятия, так и дистанционные, и, конечно же, самостоятельная работа. Особое внимание следует уделять оценке всех сделанных учащимися работ, что нередко является формальностью, к тому же используемая нами 5-бальная система (по сути, 4-х бальная) предоставляет преподавателям очень узкий коридор для оценки, диагностики, аттестации и составления рейтинга обучаемых.

Про интернет уже было все сказано, еще раз подчеркнем, что при обучении иностранному языку эта опция крайне важна, что, впрочем, относится и ко всем другим сферам образования.

Заключая аналитическую часть статьи, сформулируем следующий вывод. Обозначенные вызовы, факторы влияния, а также возможные пути оптимизации и настройки системы обучения иностранному языку можно учитывать и решать в рамках использования такого образовательного инструмента, как «Языковой портфолио».

Что означает «языковой портфолио»? Этимология итальянского слова portfolio имеет длинную и интересную историю. Во времена Возрождения в XV-XVI веках архитекторы формировали свой индивидуальный «портфолио» строительных эскизов, набросков, дизайнерских моделей и представляли его заказчику. Позднее термин стал применим в различных сферах жизни, преимущественно, в творческой среде, и имеет сегодня множество различных интерпретаций. Однако в любом случае, под термином «портфолио» понимают определенный набор, пакет, собрание работ, продуктов деятельности и материалов, выполненных автором портфолио, и представляемых соответствующему адресату с конкретной целью - например, с целью трудоустройства, поступления в ВУЗ, получения оценки, премии, определения уровня саморазвития, наконец, с целью публичного показа и демонстрации своих умений, навыков, достигнутых результатов.

В образовании использование технологии «языкового портфолио» стало на сегодняшний день устойчивым трендом, в том числе, и в России. В практику образования инструмент «языкового портфолио» вошел еще в 1972 году в США, но, пожалуй, наиболее известной для нас темой в этой связи является разработанный Отделом языковой политики Совета Европы в 1998 году и вступивший в силу в начале XXI века Европейский Языковой Портфель (ELP - The European Language Portfolio) [11]. Появлению данной технологии предшествовал базовый документ, принятый в 1996 году Советом Европы в Страсбурге под названием «Общеевропейские компетенции владения иностранным языком». Он был создан в рамках европейской интеграции как решение заказа на модернизацию образования.

Это многоуровневая система оценки языковых знаний и личностных качеств, по замыслам заказчиков и разработчиков, была призвана решать много различных образовательных задач, нацеленных в результате на развитие межкультурных связей, многоязычия, создание единого образовательного пространства, а также возрастание роли самого учащегося как личности в процессе изучения иностранных языков - за счет повышения уровня мотивации, самостоятельности и осуществления постоянной самооценки (рефлексии) своих результатов в процессе изучения иностранного языка.

В 1998 году история с развитием «языкового портфолио» начинается и в России. На базе МГЛУ возникает проект внедрения указанной системы в 12 субъектах РФ. Прошло уже более 20 лет с той поры и на сегодня можно утверждать, что методика ЯП (LP) достаточно активно вошла в жизнь наших школ. На данный момент проведено немало различного рода научных изысканий в рамках данного вопроса, осуществлены практические шаги по внедрению системы в разных образовательных учреждениях $[1,2,3,5,8,10]$. Как видно из отчетов и публикаций, данный инструмент используется в различных сферах - в начальной, средней и старшей школах, а также в вузах. Имеется дифференциация использования системы и в отношении разных возрастных групп. Авторы исследований и исполнители практик единодушно говорят об успехах и достоинствах внедряемой системы обучения.

В данной статье мы не ставим перед собой цель подробного и глубокого анализа системы ELP, но в интересах решения поставленной перед нами задачи постараемся сделать несколько обобщений. Итак, в основе предлагаемого «языкового портфолио» в отечественной системе обучения иностранным языкам предлагается классическая модель Совета Европы, суть которой состоит в следующем.

Портфолио должен состоять из 3-х частей:

- Языковой паспорт, включающий в себя личные данные человека, данные об изучении им иностранного языка, факты и опыт межязыкового общения, а также набор имеющихся сертифицированных документов об образовании, о пройденных обучающих курсах, информация об участии в конкурсах и олимпиадах, оценки на экзаменах.

- Языковая биография, в которой автор портфолио описывает хронологию изучения им иностранного языка и проводит оценку своим собственным успехам или, наоборот, неудачам и 
сложностям. В рамках ELP разработана шкала уровней владения иностранным языкам, и именно в соответствии с ней автор портфолио оценивает свои языковые умения и навыки в разных видах речевой деятельности.

- Досье демонстрирует собрание работ, проведенных автором портфолио в области освоения иностранным языком: грамматические таблицы, письменные работы, сочинения, переводы текстов и т.п

Кстати, наши российские педагоги включили в языковой портфолио 4-й компонент - т.н. «памятки» [10]. Памятки - это своего рода методички по конкретным вопросам образовательной жизнедеятельности, например, памятка о том, как нужно рационально планировать время, как работать с книгой или со статьей, как подготовиться к собеседованию, как написать личное или деловое письмо, как составить план или конспект сообщения. Представляется, что это очень плодотворная идея.

Резюмируя, можно сказать, что языковой портфолио в рамках концепции ELP - это постоянный процесс сбора обучаемых своих работ в ДОСьЕ, самоанализа процесса изучения языка в БИОГРАФИИ и, наконец, фиксации всех результатов в ПАСПОРТЕ.

Система ELP, безусловно, интересная, очень логичная, и если ей пользуются многие годы в разных странах, - значит она и эффективная. Особенно, продуктивной, на наш взгляд, она может быть в начальных школах, на раннем этапе развития личности, когда можно успешно развить навыки самооценки своих действий. Вполне вероятно, что в будущем есть целесообразность движения по данному направлению.

Тем не менее, мы в нашем вузе не можем сегодня поступить таким образом. Существуют временные, финансовые, технические, дисциплинарные факторы, препятствующие развитию такого рода системы. При этом не можем не отметить избыточный, на наш взгляд, набор требований по документам, а также по набору требований в части уже названной рефлексии (самоанализа). Психологи издавна предупреждают общество о том, что рефлексия, кроме полезных процессов самооценки, несет в себе еще и такие побочные эффекты, как «самокопание» и «накручивание», т.е. излишнее погружение в собственные переживания и отвлечение внимание от реальности на размышления типа «вот если бы», «было бы классно, если бы», называемые псевдорешениями. Однако нет сомнений в том, что навыки адекватной самооценки очень полезны в образовательном процессе.

Итак, перед нами стоит немного другая задача и с другими условиями. В начале статьи были уже обозначены насущные проблемы, вызовы и реальные сложности. Исходя из их анализа и строилась работа по оптимизации учебного процесса в целях поиска прагматичного и функционального методического инструментария. Ставилась задача конкретизации учебных целей, поиска и отбора современных учебных материалов, разработки и обучения технологиям самостоятельной работы, проведению более адекватной оценки достижений обучаемых. В ходе работы возникали разные термины по обозначению конечного результата - европейский термин «кейс», персидские слова «киф», «сандук», «махзан» (портфель, сундук, хранилище), но традиционная семантика этих прекрасных слов не давала полной картины необходимого. И вот термин «портфолио» оказался как нельзя кстати, за что спасибо архитекторам Возрождения! Итальянское слово нам показалось самым приемлемым. Поэтому в приведенной ниже структуре портфолио и технологии работы с ним не стоит искать прямых аналогий с ELP.

Таким образом, после анализа реальных учебных целей, возможных перспектив рабочего применения выпускников, была предпринята попытка составления практичного формата языкового портфолио, предназначенного как цель, инструмент, технология и оценка результата обучаемых. Его примерное содержание и структуру можно рассмотреть на образцовом примере портфолио - см. Таблицу.

\section{Структура портфолио}

Было отобрано 11 разделов, из которых 9 разделов представляют определенные виды речевой деятельности, расставленные в данной таблице в порядке значимости (разумеется, по субъективной оценке); один раздел представляет портфель знаний о стране изучаемого языка, а последний раздел к языковым знаниям прямого отношения не имеет, но ему придается особое значение.

Речевое поведение переводчика играет немаловажную роль в переговорном процессе, а также в процессе любого межязыкового общения. Внешний вид, стойка, положение рук и других частей тела, жестикуляция, мимика, интонация, громкость голоса, наличие пауз, «эканье-мэканье», эмоциональный вид - уверенный или вялый, динамика речи - ускоренная, оптимальная, замедленная, а также другие элементы речевого поведения служат показательным индикатором профессионализма, воспитания, эрудиции переводчика, и в конечном итоге непосредственно влияют на результаты коммуникации.

В структуре портфолио нет специального радела «грамматика». Во-первых, наличие знаний по грамматике и выработка навыков правильного употребления нормативной грамматики предусмотрено во всех разделах портфолио, особенно в разделах «устный пере- 
Таблица «Языковой Портфолио»

(«Практический курс первого (персидского) иностранного языка»)

\begin{tabular}{|c|c|c|c|}
\hline \multicolumn{4}{|c|}{ Демонстрация опыта, уровня обучаемого, его готовности крешению конкретных задач } \\
\hline \multicolumn{4}{|c|}{ Допуск к экзаменам и зачетам // Допуск к работе и командировкам } \\
\hline № & Компетенции & Целевые умения и навыки & Перечень выполненных работ (образцы) \\
\hline 1 & АУДИРОВАНИЕ & $\begin{array}{c}\text { Понимание основного содержания + перевод + } \\
\text { извлечение специальной информации + устное } \\
\text { изложение текста на ПЯ + написание скрипта } \\
\text { аудиотекста }\end{array}$ & $\begin{array}{c}\text { Перечень аудиотекстов различной } \\
\text { сложности (6-8 за семестр) }\end{array}$ \\
\hline 2 & ГОВОРЕНИЕ - МОНолог & $\begin{array}{c}\text { Сообщение (Презентация) на тему + рассказ о } \\
\text { событии + описание предмета/человека + умение } \\
\text { отвечать на вопросы }\end{array}$ & Список тем (6-8 за семестр) \\
\hline 3 & ГОВОРЕНИЕ - диалог & $\begin{array}{c}\text { Коммуникация в типовых ситуациях + умение за- } \\
\text { давать вопросы и отвечать на них + использование } \\
\text { речевых шаблонов }\end{array}$ & Список ситуаций (6-8 за семестр) \\
\hline 4 & $\begin{array}{c}\text { ГОВОРЕНИЕ - выражение } \\
\text { намерений }\end{array}$ & $\begin{array}{c}\text { Управление коммуникацией + выражение эмоций } \\
\text { и чувств + описание свойств и качеств предметов } \\
\text { и людей }\end{array}$ & $\begin{array}{c}\text { Список коммуникативных намерений / эмоций / } \\
\text { логико-семантических категорий }\end{array}$ \\
\hline 5 & ЧТЕНИЕ & $\begin{array}{c}\text { Понимание основного смысла + перевод (при ис- } \\
\text { пользовании словаря) + извлечение специальной } \\
\text { информации + устное изложение текста на ПЯ }\end{array}$ & Перечень текстов различной сложности \\
\hline 6 & УСТНЫЙ ПЕРЕВОД & $\begin{array}{c}\text { Устный перевод предложений (минитекстов) без } \\
\text { подготовки (запись в блокноте) = умения и навыки } \\
\text { переводчика + грамматика + лексика }\end{array}$ & Предложения (минитексты) для перевода \\
\hline 7 & ПИСЬМЕННЫЙ ПЕРЕВОД & $\begin{array}{c}\text { Письменный перевод предложений (минитекстов) } \\
=\text { знание нормативной грамматики + лексика + } \\
\text { правописание }\end{array}$ & Предложения (минитексты) для перевода \\
\hline 8 & ЛЕКСИКА & Словарный запас (активный + пассивный) & $\begin{array}{c}\text { Принципы словообразования + синонимо-антоним. } \\
\text { ряды + словообразовательные гнезда + новые } \\
\text { слова в языке }\end{array}$ \\
\hline 9 & $\begin{array}{c}\text { ПИСЬМЕННАЯ РЕЧЬ (бумага + } \\
\text { клавиатура на компьютере) }\end{array}$ & $\begin{array}{l}\text { Написание писем + письменное описание предмета } \\
\text { / человека / события + технические навыки набора } \\
\text { текстов на персидской клавиатуре }\end{array}$ & Образцы письменных документов \\
\hline 10 & СТРАНОВЕДЕНИЕ & $\begin{array}{c}\text { Лингвострановедческие знания + пословицы + } \\
\text { стихи }\end{array}$ & Дополнительная информация о стране и ее культуре \\
\hline 11 & РЕЧЕВОЕ ПОВЕДЕНИЕ & $\begin{array}{c}\text { Адекватное поведение в различных ситуациях } \\
\text { общения }\end{array}$ & Требования + принципы поведения \\
\hline
\end{tabular}

вод» и «письменный перевод», а, во-вторых, данная тема нуждается в отдельной проработке, и, надеемся, в ближайшем будущем станет предметом нашего отдельного исследования.

Обратим внимание на раздел «письменная речь». Строго говоря, сегодня переводчикам нет необходимости писать самим какие-то документы на персидском языке. Но в любом случае всегда есть необходимость, как минимум, в правильном прочтении рукописных текстов, и при этом надо понимать, что чтение персидских рукописей, - старинных, классических, современных, здесь нет особой разницы, - это всегда сложный лингвистический ребус. Отдельное внимание в процессе обучения следует уделить развитию навыков набора текстов на персидской клавиатуре, - в классическом или фонетическом форматах. В портфеле, соответственно, должны присутствовать образцы напечатанных текстов.

\section{Технология работы с портфолио}

- В начале каждого этапа (учебного года, семестра) обучения - объяснение важности, целесообразности и необходимости формирования индивидуального языкового портфолио для самих обучаемых, так и для преподавателей.

- Постановка конкретных заданий по каждому разделу портфолио, выбор заданий самими обучаемыми (в рамках консультаций с преподавателем).

- Отбор учебного материала и предоставление его 
обучаемым. Непростая задача, поскольку многие учебники персидского языка не соответствуют реалиям, но сегодня идет активная работа по написанию новых пособий и учебников. И тем не менее, всегда возникает необходимость в обеспечении обучаемых адекватными материалами по разным аспектам. В этой связи уместным будет обозначить ряд исследований, посвященных теме отбора учебного материала для обучения иноязычному общению [9], а также рассмотрению ряда иранских учебников, а также опыта преподавания персидского языка в московских вузах $[6,7]$. Еще раз подчеркнем, что при предоставлении множества разных материалов по разным аспектам необходим элементарный справочник или подробный путеводитель.

- Выбор физического (технического) формата индивидуального портфолио. Чаще всего это - отдельные папки, тетради и блокноты, флэшки с аудио и видеоотчетами, в которых разделы портфолио обозначены определенно. Надо сказать, что зачастую это представляется сложной задачей для обучаемых, однако всегда надо разъяснять, что принципы т.н. «штабной культуры» чрезвычайно важны не только в военной жизни, но и при изучении языка.

- Работа по выполнению заданий портфолио. Самый главный этап, в рамках которого каждый обучаемый понимает свои задачи в рамках индивидуального портфолио и берет на себя обязательства выполнить их за определенный период времени.

- Предоставление и демонстрация результатов работ. Как правило, в состав таких результатов входят:

- Скрипты или переводы аудиотекстов (видеороликов)

- Сообщения (Презентации) на заданные (выбранные) тему

- Представления диалогов - на занятиях или в виде видеоотчетов

- Собрание переведенных текстов с собственными словниками

- Письменные работы по переводу

- Презентации по теории грамматики вместе с собственными примерами

- Устный перевод предложений или минитекстов

- Лексические диктанты

- Коммуникативные намерения, и описание свойств и качеств предметов и людей

- Контроль, оценка и самооценка. Ряд результатов демонстрируется непосредственно на занятиях с преподавателем, ряд заданий выполняется автономно, при этом затем следует либо прямой количественный зачет работ преподавателем, либо проверка им отдельных работ на качество, либо это остается на совести каждого обучаемого. В лучших случаях полезно организовать демонстрацию работы своим коллегам, оставить презентацию или видеоотчет в фонд кафедры, а также обеспечить рекомендацию для написания курсовой работы или диплома. Следует подумать о разработке другой, альтернативной системе оценок. В нашей практике была попытка внедрения 10-бальной системы по 10 разделам (примерно соответствуют разделам языкового портфолио), и эта практика вызывала явный интерес со стороны обучаемых, особенно, кстати, в части того раздела оценок, которые выставлялись сокурсниками.

В завершение статьи сделаем вывод о том, что использование технологии и формата языкового портфолио в том виде, как он был представлен в статье, имеет ряд важных и серьезных достоинств.

Прежде всего технология портфолио представляется отражением целостной системы языковых знаний со своей определенной структурой. Преподавателем и обучаемым в процессе изучения иностранного языка, образно говоря, видны не отдельные деревья, а весь лес сверху.

Языковой портфолио дает возможность индивидуально подходить к каждому обучаемому, что помогает существенно решать извечный вопрос о том, как параллельно учить сильных и слабых учеников на одном и том же учебном материале.

Технология портфолио дает большой стимул к саморазвитию. Нельзя в этой связи не упомянуть знаменитый метод «активизации резервных возможностей личности и коллектива», разработанный Китайгородской Г.А. [4], в рамках которого большое внимание уделялось вопросам пробуждения у обучаемых дополнительной мотивации и стимуляции.

Портфолио очень удобен для текущего мониторинга и оценки успехов или неуспехов обучаемых. Здесь возможны такие опции как:

- Оценка со стороны преподавателя

- Самооценка (вижу и понимаю, что сделал сам, что умею и могу)

- Оценка коллег

Это хорошая возможность для развития креативных возможностей обучаемых - например, при создании индивидуальных или групповых презентаций или видеоотчетов.

Наконец, языковой портфолио может служить адекватной платформой для работодателей, заказчиков и кураторов различного рода служебных командировок. 


\section{ЛИТЕРАТУРА}

1. Бурцева М.Е. Языковой портфолио как инструмент становления ученика самостоятельным инновационным субъектом при изучении английского языка. // Методическая разработка. - МБОУ, г.Вязьма. - 2018

2. Ю.Е. Ваулина, Д. Дули, О.Е. Подоляко, В. Эванс. Английский язык. Языковой портфель для 5 класса, - М. 2013

3. Гальскова Н.Д. Языковой портфель как инструмент оценки и самооценки учащихся в области изучения иностранных языков // Иностранные языки в школе. - 2000. - №5. - С.6-11.

4. Китайгородская Г.А. Принципы интенсивного обучения иностранным языкам // ИяШ., - 1988.

5. Луферов Д.Н. Языковой портфолио как технология организации самостоятельной работы студентов, изучающих дисциплину «иностранный язык». // Вестник Московского государственного областного университета. Серия: Педагогика. 2017. №4. - С. 152 - 163

6. Полищук А.И. Из опыта преподавания персидского языка в Московском государственном лингвистическом университете (аспектный подход и профессиональная ориентация) // Вісник Львівского університету. Серия Філологічна. Выпуск 54. 2011. - с. 138-144

7. Потапов Ю.Б. Об иранских учебных пособиях персидского языка для начального этапа для иностранцев // Сборник статей. Язык, Культура. 0бщество. M., 2020. - C-190-198

8. Сагитова Р.Р., Валеева Р.3. Языковой портфолио как средство формирования самообразовательной компетенции студентов гуманитарного вуза в процессе обучения иностранным языкам // Казанский педагогический журнал. - 2017.

9. Соболев В.В. Методика отбора учебного материала для начального этапа обучения иноязычному общению (специальный вуз, персидский язык) // Диссертация кандидата педагогических наук. - М., 1992.

10. Тялева И.А. Технология портфолио в обучении иностранному языку. // Севастопольский городской гуманитарный университет, 2012.

11. European Language Portfolio: Teachers Guide - third edition / CILT, the National Centre for Languages, 2006

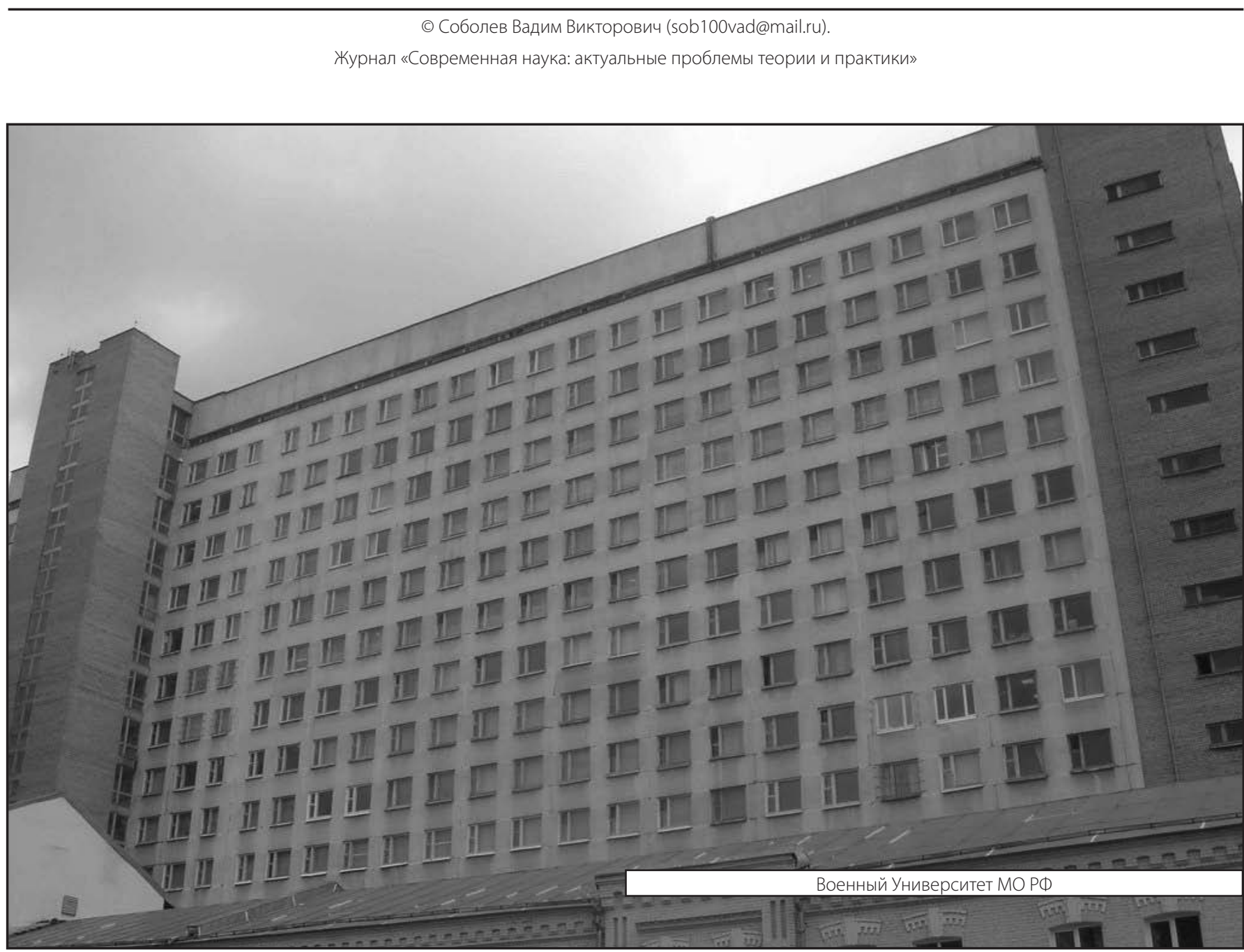

